\title{
Correspondence Between Reliability of Rental Flat Building and Space Needs
}

\author{
Rita Laksmitasari Rahayu ${ }^{1, *}$, Huri Suhendri ${ }^{2}$, Rimsa Rusmiland ${ }^{3}$ and Indah Yuliasari ${ }^{4}$ \\ ${ }^{1}$ Lecturer, Universitas Indraprasta PGRI \\ *Corresponding Author: ritalaxmi@gmail.com
}

Article history

Received: 04.08.2020

Revised: 17.09.2020

Accepted: 22.09.2020

DOI:10.31629/jit.v1i2.3168

\begin{abstract}
Flats for rent need to be designed so that residents move comfortably and can save themselves in times of disaster. This research was conducted with the aim of knowing the spaces needed by the occupants by taking into account the reliability of the building-safety and comfort. Some aspects of building reliability are motion comfort and safety. Data was collected by an online questionnaire, which was distributed to residents using non-random sampling. The collected text data was analyzed by content analysis. From the results of the analysis revealed that residents tend to be comfortable moving in rental residential units. Residents need a secondary space that is a shelf and work space. Storage space represents the meaning of storage of small items. Work, study and storage of equipment represent the meaning of workspace needs. Residents need some secondary space in a residential unit that has aspects of motion comfort and security during disaster evacuation. Motion comfort mainly represents a little furniture, has storage space, and doesn't interfere with activities like sitting and watching television. The number of residents felt safe moving when disaster evacuation in vertical housing was almost the same as the number of residents who felt the evacuation route was not ideal. Easy access is achieved, wide circulation room, near the emergency stairs is represented by the meaning of feeling safe moving during a disaster evacuation. There is no special emergency ladder, narrow circulation space, the condition of a damaged staircase at the time of disaster evacuation is represented by meaning not ideal. This study found a significant relationship between the reasons for motion comfort and the presence of space requirements. There is no significant relationship between disaster evacuation security and secondary space requirements.
\end{abstract}

Keywords: rental flats, building reliability, motion comfort, safety and space

\section{Introduction}

Provision of decent housing for the people in Indonesia, especially for Low-Income Communities (MBR) is one of the programs to improve the quality of life and one of the priority programs of the Indonesian government. Safety and comfort aspects of movement in buildings are included in the reliability of buildings (Law No. 28 of 2002 article 16 [1]. One of the government programs is by providing rental apartments.

Residents of rented flats need a space that is comfortable and safe during evacuation. The primary space needs consist of shared space, 
bedroom, dining room, kitchen, laundry room, and bathroom. Activities and occupation professions that are diverse require some secondary space. Among the secondary spaces are storage space and space for activities. Storage of goods becomes clearer, residential units become tidy, and affects the comfort of occupants' movements. The grouping of several activities which are almost the same is done in one room and the storage of equipment is well organized.

Residents feel safe during disaster evacuation. A sense of security is a feeling that must first be presented to the occupants. When and shortly after the earthquake struck, people moved irregularly to save themselves. People move in an unorganized manner and cannot wait to find a way to save themselves [2]. This condition will get worse if the occupants cannot choose the right, fast, and easy evacuation route.

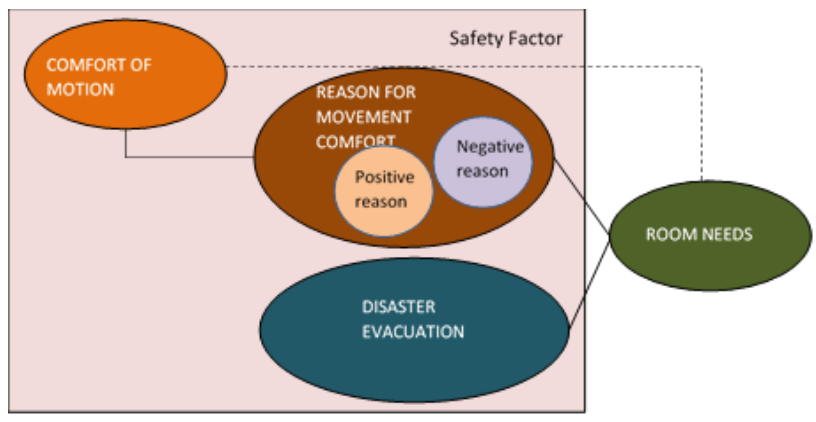

Figure 1. Relationship between safety and space requirements

It is hoped that the results of this study can be used by architects, developers, investors, and owners of residential units. The results of the study can also be seen as an illustration of the needs of occupants in their homes for them to be satisfied and have impact on their productivity.

The existence of space is limited by fields both horizontally and vertically. Space has at least a horizontal plane, both raised base, lowered base, even floating base. Space is also formed by vertical elements, both vertical elements only linearly, plane (1-4 planes). It is clear that in order to present space as a place of activity, it does not need space that is limited by 4 fields. Space (space) is planned as a container of the activities of its inhabitants who have an expression of 3-dimensional quality. The shape and enclosure of each space in a building will determine or be determined by the shape of the surrounding spaces [3].

Space accommodates one or more activities from users. Space is limited by imaginary and physical boundaries. Likewise, the user's movement activities move within one activity to another, from one room to another room, or from one building to another building. The smallest part of the building is the space used in just one activity. Personal space is the space around individuals who have personal or private values. Despite the extensive limitations of low-cost housing, personal space must also be noted. The nature of personal space can be distinguished based on interpersonal distance, namely intimate distance, personal distance, social distance, and public distance. In general, personal space is needed by each individual to move with the nature of space that has a personal distance.

The distance of personal space is influenced by gender, age, personality, psychological disorders, conditions of disability, attraction, security / fear, competition / cooperation, power and status, physical environment influence [4].

Inter-room organizations have a goal to accommodate the activities of residents. Good spatial planning increases the productivity of the lives of tenement rental residents. Activities of residents are contained by space. The comfort of the occupants can be seen from the well-organized activities in a building.

The rights of space users in their activities also need to be considered including residential units. The limitations of area and cost do not eliminate the right of occupants to own personal space. Privacy is the ability of one or a group of individuals to sustain life and its affairs from or to control the flow of information about themselves [4,5].

Residents carry out activities in the form of a system of division of labor, cooperative activities, and communicating in the life of human groups. Occupant activities have a nature not based on instinct because humans have reason. The variety of human behavior is indeed not due to racial characteristics, but because groups where these people interact and interact in large groups (countries). In smaller groups (territories), more specialized human entities, different from one another, are caused by the customs and language of ethnic groups, sometimes also because of religion or a combination of the two [6].

Basic activities as a family that has the norm of a happy and prosperous small family in accordance with the values of religious and social values that are entrenched in personal, family, and society, oriented to the welfare life with the ideal number of children to realize birth welfare and inner happiness. The activity of the flat apartment residents in the apartment units with the number of occupants of 1 person or 2 people (husband and wife) is a form of 
quality family with basic and routine activities in the family.

Residents of the apartment will look for a rescue route to a place that they consider as safe space. The rescue route uses a wayfinding system. Wayfinding systems do not simply put the signboard and use color codes to distinguish various areas of the hospital [7].

Wayfinding devices use maps, road numbers, and direction signs and so on other article [8]. Wayfinding design is very important for facility users in understanding the environment based on the concept of spatial orientation and the prerequisites are cognitive maps [9].

As a safety requirement, pay attention to disaster evacuation routes, for example fire, earthquake and flood disasters. Easy and convenient accessibility starts from inside the apartment unit and goes to the evacuation gathering point. Convenient access includes horizontal and vertical access. Rental apartments provide emergency stairs as a means of vertical transportation for evacuation. Horizontal access to the evacuation paths of flats has wide corridors which are quite comfortable to use. As one of the requirements for emergency stairs is that residents have accessibility - vertical transportation of various ages and conditions.

\section{Methodology}

This research uses a quantitative analysis approach. Data collected by survey-filling questionnaire. Distribution of questionnaire sheets through social media (online). Respondents were restricted to vertical occupants who had the same opportunity to fill out a questionnaire. Online questionnaire was distributed freely using nonrandom sampling to fellow researchers, then the questionnaire was distributed back to the occupants through social media accounts in the form of the WhatsApp application.

The collected text data were analyzed with content analysis to see the distribution, co-incidence between categories, and cluster analysis. This online questionnaire contains questions compiled using open-ended and close-ended questions. Close-ended form of respondents' attributes, such as gender, age, last education, and occupation. Open ended in the form of questions with the answers to motion comfort, reasons of comfort, and some space needed for certain activities and equipment storage. Another question is the convenience of living in vertical housing and the view of the disaster evacuation route. The answers to the questions were analyzed using content analysis with several stages, namely:

1. Open coding, the answer to open ended is determined by several keywords.

2. Axial coding, the results of key words in the first stage are grouped based on similarity into one category. Then the categories are distributed using distribution analysis.

3. Selective coding, looking at the relationship between spatial requirements, motion comfort and disaster evacuation through correspondence analysis. At this stage, data processing uses cluster analysis. Several categories are grouped according to similar characteristics.

Data collection through online questionnaires was conducted from 20 June 2019 until 6 July 2019. The total respondents obtained were 101 people, 50 women and 51 men

\section{Results and Discussion}

In the open coding stage, answers from the occupants about the space requirements are found in several words, namely "studying, working, storing computers, displaying works". Some keywords are found in the question of motion comfort such as "wide space, comfortable enough, broken walls make limited motion, too many screens". Some keywords "near the emergency stairs, such as inadequate, feel insecure are found on the question of disaster evacuation".

The next step, the researchers conducted axial coding, where the keywords generated from open coding were categorized into 11 categories of space requirements such as: kitchen, pantry, shelf, transition room, linen room, work space, warehouse, hobby room, janitor, shared space. Axial coding of the keyword motion comfort consists of 4 categories of motion comfort in a residential unit namely: "very uncomfortable, uncomfortable, quite comfortable, comfortable, very comfortable". Reasons for the comfort of movement in residential units are grouped into several categories, such as: limited unit area, efficient layout, use of inappropriate furniture, and limited circulation. The axial coding stage, in the sense of security during disaster evacuation, there are 4 categories: "feel safe, doubtful, not ideal, enough". In determining the space requirements, 
the comfort of movement in the residential unit, and the sense of security during disaster evacuation, can be seen in table 1 , table 2 , table 3 , and table 4.

Table 1. Examples of axial coding for motion comfort in residential units.

\begin{tabular}{|c|c|c|}
\hline No & Keywords & Category \\
\hline 1 & Lots of big stuff & Not Comfortable (53) \\
\hline 2 & Many residents & \\
\hline 3 & Room insulated & \\
\hline 4 & Limited unit area & \\
\hline 5 & $\begin{array}{l}\text { Limited circulation } \\
\text { pathway }\end{array}$ & \\
\hline 6 & The room is not neat & \\
\hline 7 & Efficient layout & Quite comfortable (23) \\
\hline 8 & Simple life & \\
\hline 9 & No problem & \\
\hline
\end{tabular}

Table 2. Examples of axial coding reasons for comfort in a residential unit.

\begin{tabular}{|c|c|c|}
\hline No & Keywords & Category \\
\hline 1 & Less extensive & \multirow[t]{6}{*}{ Limited unit area (23) } \\
\hline 2 & $\begin{array}{l}\text { Limited sleeping } \\
\text { space }\end{array}$ & \\
\hline 3 & Room insulated & \\
\hline 4 & $\begin{array}{l}\text { There is no storage } \\
\text { space }\end{array}$ & \\
\hline 5 & Small spaces & \\
\hline 6 & $\begin{array}{lll}\text { Lots of } & \text { room } \\
\text { dividers } & & \\
\end{array}$ & \\
\hline 7 & Efficient structuring & \multirow[t]{3}{*}{ Efficient layout (20) } \\
\hline 8 & Unlimited motion & \\
\hline 9 & Easy to put furniture & \\
\hline
\end{tabular}

Table 3. Examples of axial coding for comfort in the evacuation route

\begin{tabular}{|c|c|c|}
\hline $\mathrm{No}$ & Kata Kunci & Kategori \\
\hline 1 & Narrow corridor & Not ideal (33) \\
\hline 2 & $\begin{array}{l}\text { The stairs are not } \\
\text { wide enough }\end{array}$ & \\
\hline 3 & Many residents & \\
\hline 4 & $\begin{array}{l}\text { Narrow evacuation } \\
\text { access }\end{array}$ & \\
\hline 5 & Lots of broken stairs & \\
\hline 6 & Hard to reach & \\
\hline 7 & Easy access & Feel safety (33) \\
\hline 8 & $\begin{array}{l}\text { Near the emergency } \\
\text { stairs }\end{array}$ & \\
\hline 9 & $\begin{array}{l}\text { The stairs are quite } \\
\text { wide }\end{array}$ & \\
\hline 10 & $\begin{array}{l}\text { There is a security } \\
\text { tool }\end{array}$ & \\
\hline
\end{tabular}

From the categorization, obtained 5 categories of motion comfort in the occupancy unit, 9 categories of reason of motion comfort, and 4 categories of results from the analysis of the distribution of space comfort in the occupancy unit according to the occupants can be seen in Figure 1. Residents feel uncomfortable in the residential unit of 53 people $(52 \%)$, residents feel quite comfortable as many as 23 people $(23 \%)$, and residents feel comfortable as many as 19 people $(19 \%)$. The occupants of the other residential units chose very comfortable 5 people $(5 \%)$ and very uncomfortable 1 person (1\%).

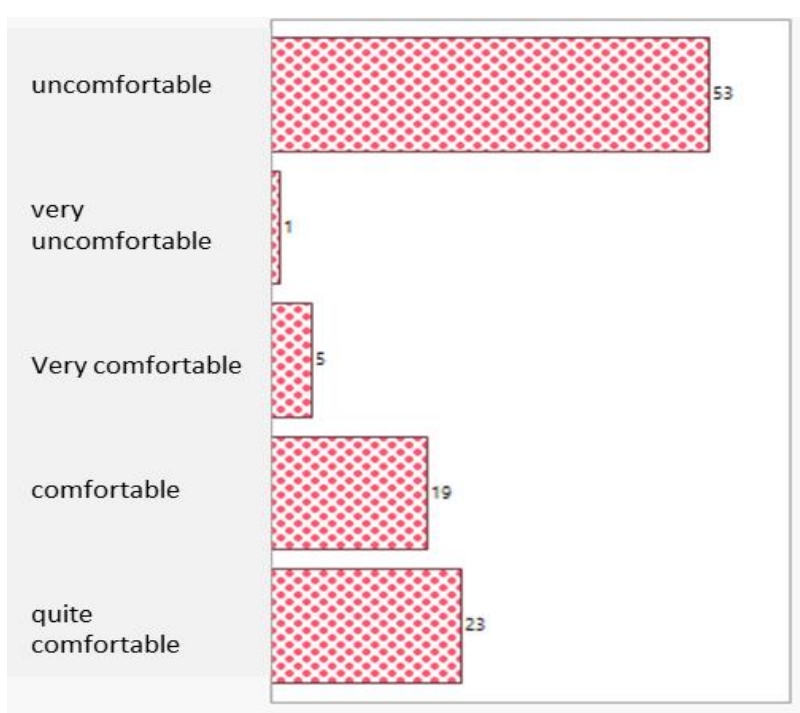

Figure 2. Analysis of the distribution of space comfort in residential units according to occupants

Most residents feel uncomfortable moving around in residential units, for reasons: many large items, dense occupants, insulated space, limited unit area, limited circulation paths, and untidy space. The results of the analysis of the distribution of the reasons for comfortable mobility in residential units according to the occupants can be seen in Figure 2. The reason for the limited area of the unit chosen by the occupants feel uncomfortable moving.

Keywords of occupants choose the area of limited units are less spacious residential units, limited sleeping space, insulated space, no storage space, and narrow spaces. Of the 9 categories of reasons for comfortable motion in residential units, the reason for the limited area of the unit and the efficient layout into 2 dominant reasons. Occupants of residential units have the reason of 
the limited unit area being the most reason (23\%) and the efficient layout of $20 \%$.

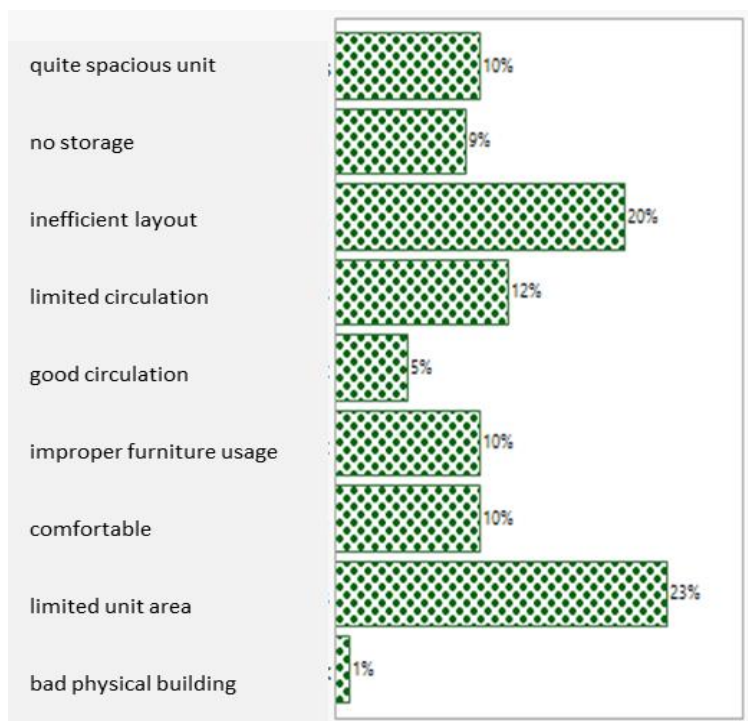

Figure 3. Analysis of the distribution of reasons for comfortable motion in residential units according to occupants

In categorizing the sense of security at the time of disaster evacuation there are 4 categories, and 10 categories of space requirements in residential units. The results of the analysis of the distribution of a sense of security during a disaster evacuation can be seen in Figure 3. Residents feel safe when evacuating as many as 33 people $(33 \%)$, residents feel quite safe as many as 25 people $(25 \%)$, residents feel not ideal as many as 33 evacuation facilities people (33\%), and residents have doubts as many as 10 people (19\%).

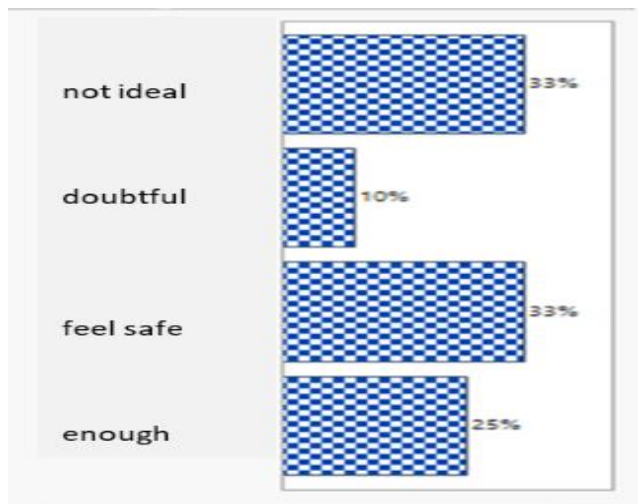

Figure 4. Analysis of the distribution of residents' sense of security at the time of a disaster evacuation
Table 4. Examples of axial coding space requirements for residents

\begin{tabular}{|c|c|c|}
\hline No & Keywords & Category \\
\hline 1 & Clothes & \multirow[t]{4}{*}{ Shelf save (53) } \\
\hline 2 & Pants & \\
\hline 3 & Children toys & \\
\hline 4 & Body care equipment & \\
\hline 5 & Read the book & \multirow{4}{*}{$\begin{array}{l}\text { Workspace } \\
\text { (21) }\end{array}$} \\
\hline 6 & $\begin{array}{l}\text { Working with } \\
\text { computers }\end{array}$ & \\
\hline 7 & Save work equipment & \\
\hline 8 & Display assignments & \\
\hline
\end{tabular}

Residents need shelves in their residential units as many as 53 people (36\%) and 21 people (14\%) who need work space. The results of the analysis of the distribution of space requirements for residents can be seen in Figure 4. The kitchen is the space needed by residents as much as $10 \%$ and the pantry needed by residents as much as $9 \%$. Some space is needed by residents as much as $8 \%$, namely the transition room, hobby room, and shared space. Transition space is a group of space requirements from the transition of activities in space to outdoor activities.

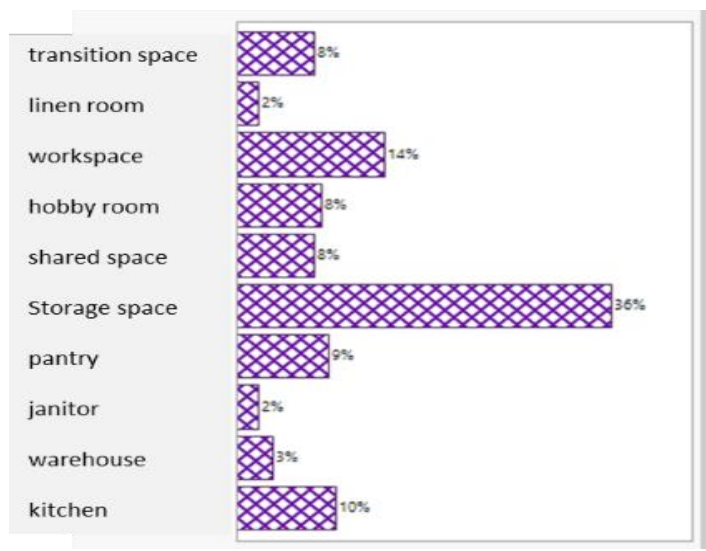

Figure 5. Analysis of the distribution of occupant space requirements

The next step is to do selective coding with correspondence analysis that will reveal the level of closeness / co-incidence between the comfort of motion in the residential unit with the space requirements. The method of grouping with two or more keywords that has the closest similarity. Then the process is forwarded to other keywords that have a second closeness. And so on, so that the cluster will form a kind of "tree", such as a clear hierarchy or level between keywords, from 
the most similar to the least similar. Logically all keywords will eventually form a cluster. The dendogram below clearly shows the hierarchical process.

Furthermore, the motion comfort category and the occupational space needs category are seen as the closest similarity (hierarchical method). Researchers also see the closest similarity to the category of reasons for the comfort of motion in residential units and the spatial needs category. For this reason, the relationship between comfort and space requirements will be seen in the correspondence. Correspondence analysis is carried out using ward hierarchical clustering, the results of which can be seen in Fig. 6 and Fig. 7.
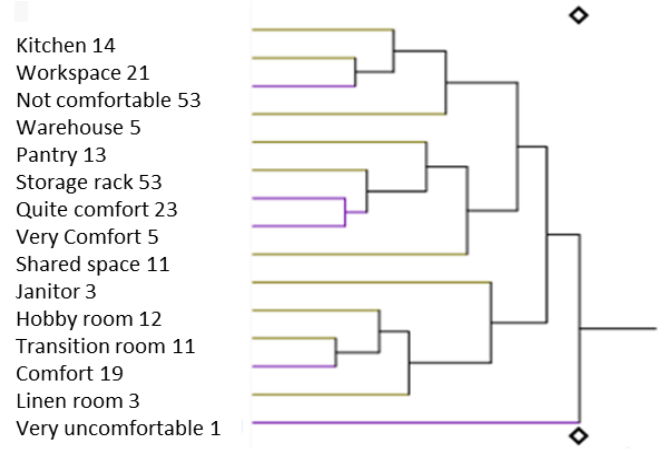

Figure 6. Dendogram between motion comfort categories and space requirements

In the dendogram above, it appears that many residents need a shelf to store in their residential units and feel they do not have the comfort of movement in their homes. The discomfort of motion is felt by the occupants due to the limited area of the unit. Many items that need to be stored in an orderly manner require shelves that are effective and efficient in these limited units.

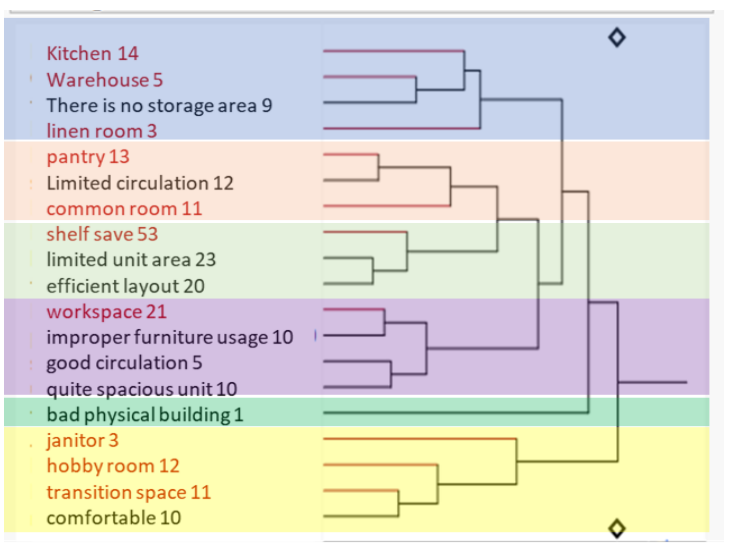

Figure 7. Dendogram between motion comfort categories and space requirements
The reason for the convenience of moving to a limited unit area and units that have an efficient layout requires a shelf store. Circulation is limited as a reason for moving comfort, so residents need a pantry and a shared space. The reason for the convenience of occupants moving requires a kitchen, warehouse, and linen space because there is no storage space. The use of furniture is not right, good circulation, and the unit is spacious enough is the reason for the comfort of the occupants' motion requires work space. Seen in figure 8 , the dominant respondent's occupation is as an employee (43\%) and entrepreneur as much as $31 \%$.

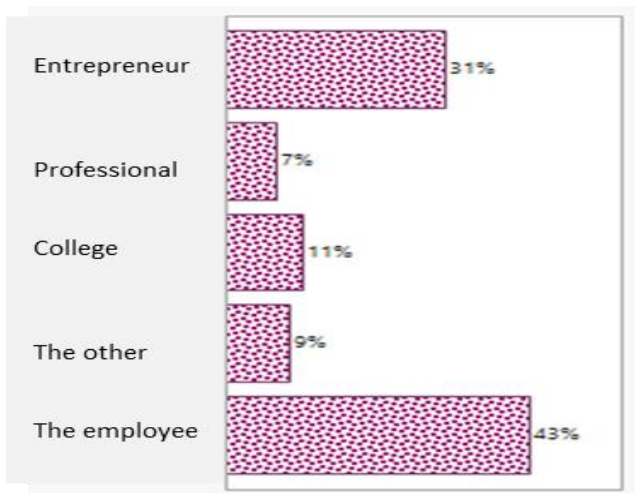

Figure 8. Analysis of occupant employment distribution

The next stage is selective coding through correspondence analysis. Based on the analysis of motion comfort and space requirements, a Pearson significant value (p) of 0.2940 (not significant) was obtained. This value means the possibility of incorrect prediction is $29.4 \%$.

Based on the results of the analysis of the reasons for space comfort and space requirements, a Pearson significant value (p) of 0.0358 (significant) was obtained. This value means the probability of accuracy prediction is $3.58 \%$.

Pearson Significance has a value of 0.0358 for the category of reasons of comfort and space requirements, likelihood or risk of errors in the results of tests conducted. In the dendogram above (Figure 8) six clusters can be seen.

The results of the study are reasons for the convenience of motion and space requirements in the apartment housing units have a small Pearson significance. Residents need a shelf and work space. Architects can apply the results of this study to the design of flats, as on Figure 9. 


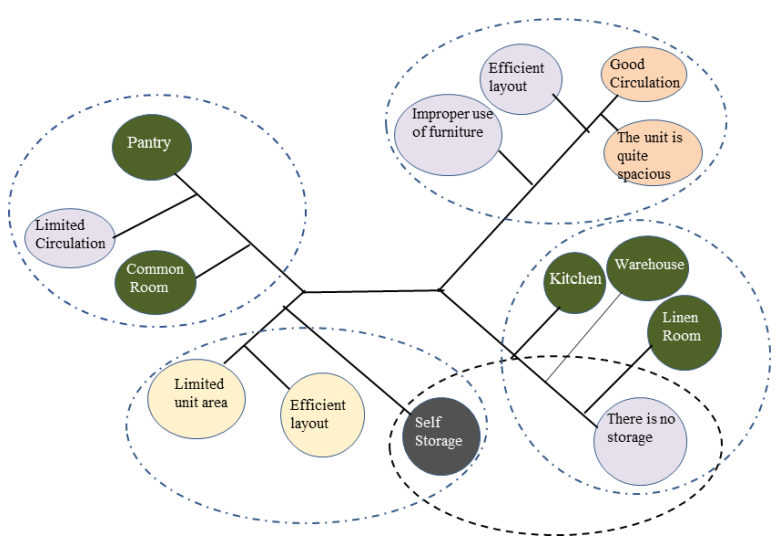

Figure 9. Relationship between the reasons for motion comfort and space requirements

\section{Conclusion}

The conclusion from this study the reason for discomfort for residents is the limited unit area. Many items that need to be stored in an orderly manner require shelves that are effective and efficient in these limited units. The closeness of the relationship or co-incidence between categories of reasons for motion comfort and space requirements has little value, so the closeness of the relationship is large. Occupant occupation factor. This research forward on conducting multivariate regression analysis in order to find the close relationship between several categories as causes such as the type of vertical occupancy, work, and moving comfort in the aisles. The study uses a non-experimental quantitative research approach to look for meaning in quantitative research, and researchers use numbers in regression (Principal Component Analysis and Factor Analysis).

\section{Acknowledgement}

The Directorate of Research and Community Services, Director General of Research and Development Strengthening, Ministry of Research, Technology and Higher Education through national competitive research activities in PDUPT F.Y. 20182019 with the title: "Evaluation of Safety Requirements - Building Reliability Against Motion Comfort in Rental Flats in Jakarta". Also to Institute of Research and Community Service at Indraprasta University, PGRI, for helping with this research activity through the Research Contract No.: 0407 / SKP.LT / LPPM / UNINDRA / III / 2019.

\section{References}

[1] Carpman, J. dan Grant, M. Design that cares: Planning Health Facilities for Patients and Visitors (2nd ed.). (Chicago: American Hospital Publishing, 1993).

[2] Ching, F.D (1984). Arsitektur Bentuk Ruang dan Susunannya. Jakarta: Erlangga

[3] Creswell, J. W. Research Design Qualitative, Quantitative, and Mixed Methods Approaches. 4th edition. (Thousand Oaks, CA, SAGE. 2014)

[4] Drs Jaenudin, Ujam, M.Si. (2017) Psikologi Lingkungan, Bandung: CV Pustaka Setia

[5] Groat, L. \& Wang, D. Architectural Research Methods. (New York: John Wiley \& Sons. Inc. 2002).

[6] Koentjaraningrat, (2015). Pengantar Ilmu Antropologi. Jakarta: Rineka Cipta

[7] Nateghi-Alahi, Fariborz \& Izadkhah, Yasamin O. Earthquake Mitigation In Health Facilities In Mega City Of Tehran. 13 th World Conference on Earthquake Engineering Vancouver, Canada. Paper No. 3116. (2004)

[8] Neuman, W. Lawrence. Social Research Methods: Quanlitative and Quantitative Approarch, 7th edition, (Pearson Education, Inc. Boston, 2017).

[9] Rooke. C. N., Tzortopolous. P, Koskela. L. J., dan Rooke. J. A. Wayfinding: Embedding Knowledge In Hospital Environments. Proceedings HaCIRIC Improving Healthcare Infrastructures Through Innovation. Brighton UK. 158-167 (2009) 